\title{
Identificação e controle do Alternanthera mosaic virus isolado de Torenia sp. ${\text { (Scrophulariaceae) })^{(1)}}$
}

\author{
LÍGIA MARIA LEMBO DUARTE (2), ANA NÓBREGA TOSCANO ${ }^{(1,2)}$, MARIA AMÉLIA VAZ ALEXANDRE(2), ELIANA BORGES \\ RIVAS $^{(2)}$ e RICARDO HARAKAVA ${ }^{(2)}$
}

\begin{abstract}
RESUMO
O mercado de flores e plantas ornamentais vem crescendo consideravelmente nos últimos anos, no Brasil. É importante destacar que, paralelamente ao crescimento das exportações, um aumento na importação de flores e plantas ornamentais vem sendo observado. Porém, apesar da introdução de novas espécies e variedades, são poucos os relatos de doenças causadas por vírus, possivelmente porque alguns induzem infecção latente, dificultando sua identificação. Assim, este trabalho teve como objetivo identificar biológica, sorológica e molecularmente o vírus presente em plantas de Torenia sp. assintomáticas, provenientes de região produtora do Estado de São Paulo. Além disso, uma medida de controle alternativo foi proposta. Verificou-se que o vírus isolado de torênia induziu, em hospedeiras experimentais, sintomas semelhantes aos causados por espécies do gênero Potexvirus. Este resultado foi confirmado por RT-PCR, utilizandose oligonucleotídeos específicos para potexvirus. Testes sorológicos, bem como análises das sequiências obtidas e filogenéticas foram fundamentais para a identificação do Alternanthera mosaic virus (AltMV), denominado de AltMV-T. Convém salientar que este vírus, assim como os potexvirus, de modo geral, são disseminados na cultura por instrumentos de poda e por contato. Visando um controle eficiente e de baixo custo, extrato foliar de Mirabilis jalapa foi pulverizado em plantas de Chenopodium amaranticolor, antes do corte das folhas com lâmina previamente imersa em inóculo viral. Verificou-se uma inibição da infecção causada pelo AltMV-T em 83\%. Esse resultado viabiliza a utilização de extrato foliar de M. jalapa, antes dos procedimentos de desbaste das plantas, minimizando-se a disseminação do vírus pela cultura.
\end{abstract}

Palavras-chave: Horticultura ornamental, Potexvirus, filogenia, controle alternativo, inibidores naturais

\begin{abstract}
Identification and control of Alternanthera mosaic virus isolated from Torenia sp. (Scrophulariaceae)

In Brazil, the ornamental and flowering plant market has gained wide acceptance in the last years. It is worth mentioning that simultaneously to the increase in the Brazilian exports, an increase in the flowers and ornamentals imports has also been noted. However, despite the introduction of new botanical species and varieties, reports of viral diseases are scanty, probably due the latent form of some viruses that precludes their symptoms manifestation. The aim of this study was to identify by biological, serological and molecular means a virus in asymptomatic Torenia sp. from growing areas of the São Paulo state. In addition, an alternative control method was proposed. On mechanically inoculated hosts, the Torenia virus induced Potexvirus-like symptoms. RT-PCR analysis was positive for Potexvirus when specific primers were used. Serological tests, sequencing and the phylogenetic analyses were conclusive for the identification of Alternanthera mosaic virus (AltMV), herein referred to as AltMV-T. Potexviruses, and also AltMV$\mathrm{T}$, are generally spread in crops through cutting tools and contact. With the aim of efficiently and economically controlling the viral contamination, foliar extract of Mirabilis jalapa was sprayed on Chenopodium amaranticolor prior leaf cuttings were made with blades previously dipped in the viral inoculum. It was noted that the infection by AltMV-T was reduced at $83 \%$ in sprayed C. amaranticolor. This result indicates the potential importance of $M$. jalapa extracts for reducing the virus dissemination during cultural practices in the crop.
\end{abstract}

Key words: ornamental horticulture, Potexvirus, phylogeny, alternative control, natural inhibitors

\footnotetext{
${ }^{(1)}$ Parte da Monografia de conclusão de curso da segunda autora. Recebido em 20/12/2007 e aprovado para publicação em 18/02/2008.

Laboratório de Fitovirologia e Fisiopatologia/CPDSV, Instituto Biológico, Av. Conselheiro Rodrigues Alves, 1252 - CEP: 04014-002, São PauloSP). e-mail: duarte@biologico.sp.gov.br
} 


\section{INTRODUÇÃO}

O mercado de plantas e flores ornamentais vem crescendo nos últimos anos, com a ampliação das regiões produtoras em vários estados da Federação (JUNQUEIRA e PEETZ, 2007). Entretanto, São Paulo é o maior produtor, responsável por $70 \%$ da produção nacional (KIYUNA et al., 2002).

Segundo a Secretaria de Comércio Exterior do Ministério do Desenvolvimento (SECEX/MDIC), o comércio mundial de produtos da floricultura em 2006 obteve um aumento de $14,8 \%$ com relação ao ano anterior. A balança comercial de floricultura brasileira continua mantendo-se altamente favorável ao País, com saldo positivo de U\$ 12 milhões, no período de janeiro a junho de 2007 (JUNQUEIRA e PEETZ, 2007). No entanto, o principal grupo de produtos em vendas externas continua sendo o de mudas $(48,3 \%)$, seguido por bulbos, flores frescas e folhagens (KIYUNA et al., 2007).

Apesar da constante introdução de novas espécies e variedades de plantas ornamentais, existe uma escassez de informações, especialmente no que se refere às viroses, que podem causar prejuízos à cultura, diminuindo a produção, resultando em plantas e flores sem qualidade e se tornando, em alguns casos, barreiras à exportação (ALEXANDRE et al., 2005a). Portanto, embora o Brasil figure como um país altamente promissor no mercado internacional de flores e plantas ornamentais, os problemas fitossanitários ainda são obstáculos que devem ser superados para o crescimento das exportações brasileiras (JUNQUEIRA e PEETZ, 2002), especialmente no que se refere às doenças causadas por vírus.

Dentre as plantas ornamentais mais cultivadas, tem sido detectada a ocorrência de vírus, com maior frequiência, em Alstroemeria sp., Chrysanthemum sp., Dieffenbachia sp., Eustoma grandiflorum, Gladiolus sp., Gloxinia sp., Hippeastrum sp., Impatiens spp., Lilium sp. e orquídeas (ALEXANDRE et al., 2005b). Até o momento, não foi registrada a ocorrência de vírus em torênia, muito provavelmente devido a recente introdução dessa ornamental no comércio brasileiro. Entretanto, recentemente, o Laboratório de Fitovirologia e Fisiopatologia (LFF/IB) recebeu amostras de Torenia sp. (Scrophulariaceae), provenientes de região produtora de São José do Rio Preto (SP), aparentemente sem sintomas, para análise da presença de vírus.

É importante destacar que o controle das fitoviroses é difícil e, até o momento, não existem substâncias com ação "viricida”. Assim, para minimizar os danos causados pelos fitovírus, medidas baseadas principalmente na eliminação das fontes de infecção e dos vetores têm sido utilizadas (HULL 2002), porém, nem sempre com sucesso. Dessa forma, medidas alternativas podem ser obtidas também para vírus que infectam espécies ornamentais, utilizando-se extratos foliares de espécies pertencentes à ordem Caryophyllales com atividade antiviral, já testados no controle alternativo de vírus que infectam culturas importantes como tomate, batata e abobrinha da moita (DUARTE et al., 1990, 1995, NORONHA et al., 1996, TOZETTO et al., 2002).
O presente trabalho teve por objetivos identificar biológica, sorológica e molecularmente o vírus isolado de Torenia sp., proveniente de região produtora do Estado de São Paulo, bem como propor uma medida de controle alternativo para esse vírus.

\section{MATERIALEMÉTODOS}

\subsection{Material}

O vírus foi isolado de Torenia sp. (figura 1), aparentemente sem qualquer tipo de sintoma (infecção latente), proveniente de São José do Rio Preto (SP), enviada para o LFF/IB para análise da presença de vírus.

\subsection{Transmissão Mecânica}

O extrato vegetal empregado nos ensaios de inoculação mecânica foi preparado pela homogeneização de folhas infectadas em presença de tampão fosfato 0,01 M, pH 7,0 acrescido de 0,04 M de sulfito de sódio (TI). Os extratos foram inoculados nas plantas indicadoras das famílias: Amaranthaceae (Amaranthus viridis, Alternanthera brasiliana, A. tenella, Celosia sp., Gomphrena globosa), Chenopodiaceae (C. amaranticolor, C. quinoa, C. murale), Solanaceae (Datura stramonium, Nicotiana benthamiana, N. clevelandii, N. debneyi, N. glutinosa, N. megalosiphon, N. sylvestris, N. tabacum 'White Burley', N. tabacum 'Xanthi'), Portulacaceae (Portulaca oleraceae var. sativa), Asteraceae (Zinnia elegans) e Scrophulariaceae (Torenia sp.).

\subsection{Transmissão por Lâmina de Corte}

O teste de transmissão por lâmina de corte (estilete) foi realizado cortando-se a região das nervuras primária e secundária de $C$. amaranticolor, após a imersão da lâmina em inóculo 1/5 (P/V), preparado a partir de um grama de folha de $C$. amaranticolor experimentalmente infectado para $5 \mathrm{~mL}$ de TI.

\subsection{Sorologia}

ELISA indireto foi realizado a partir de extratos foliares infectados e sadios (controle) preparados na concentração de 1/10 (P/V). Foi utilizado anti-soro contra Alternanthera mosaic virus (AltMV), gentilmente cedido pelo Dr. J. E. Thomas, da Queensland Horticulture Institute (Austrália). O método empregado foi descrito por KOENIG (1981). Leituras de absorbância (405nm) foram feitas após a aplicação do substrato (p-nitrofenilfosfatase), sendo os resultados analisados pela relação da média das leituras das amostras infectadas (triplicata), sobre a média das amostras sadias (I/S). Foram consideradas positivas, as amostras com leitura três vezes superior à média dos controles.

\subsection{Extração de RNA, RT-PCR e seqüenciamento}

Os RNAs totais foram extraídos utilizando-se o "RNeasy plant minikit" (Qiagen), conforme recomendação do fabricante, a partir de amostras foliares de $C$. amaranticolor sadio (controle negativo) e sistemicamente infectado com o vírus em estudo e de $N$. tabacum 'White Burley' sistemicamente infectada com o Potato virus $X-$ PVX (controle positivo). 
As reações de transcrição reversa $(\mathrm{RT})$ e em cadeia da polimerase (PCR) foram realizadas nas condições descritas por GIBBS et al. (1998), utilizando-se os oligonucleotídeos universais para potexvirus. Os produtos de PCR obtidos foram analisados em gel de agarose $2 \% \mathrm{e}$ visualizados em um transiluminador (UV).

Os fragmentos amplificados foram excisados do gel, purificados com o "kit Perfectprep Cleanup" (Eppendorf), conforme orientações do fabricante e clonados em pGem-T (Promega Corp, Madison, W). Dois clones foram seqüenciados pelo sistema "ABI Prism Big Dye" (PE Applied Biosystems).

\subsection{Análise das Seqüências}

As seqüências de nucleotídeos (nt) foram submetidas ao BLAST - "Basic Local Alignment Search Tool" (ALTSCHUL et al. 1990), alinhadas manualmente e automaticamente traduzidas, usando o programa SeqPup V. O.6 f (GILBERT, 1995) e o grau de identidade entre as sequiências de nt e de aminoácidos (aa) deduzidos foi determinado utilizando-se o programa PAUP v.40b10.

\subsection{Análise Filogenética}

Sequiências de nt e aa do vírus em estudo e de espécies de Potexvirus foram submetidas à análise de máxima parcimônia (MP), utilizando-se o programa PAUP v.40b10 (SWOFFORD, 2002), com busca heurística.

\subsection{Controle Alternativo}

O extrato contendo substância inibidora de infecção viral foi preparado na concentração de um grama de folhas de Mirabilis jalapa para $10 \mathrm{~mL}$ de água destilada, filtrado em gaze e acrescido de $100 \mathrm{~mL}$ de "Tween 20" (P/V; $1 / 10)$.

O inóculo (extrato viral) foi preparado a partir de um grama de folhas de $C$. amaranticolor infectado com o AltMV-T para $5 \mathrm{~mL}$ de sulfito de sódio a $0,5 \%$ (P/V; 1/10).

Cinqüenta $\mathrm{mL}$ do extrato foliar de $M$. jalapa foram pulverizados em dez plantas de $C$. amaranticolor que, em seguida, foram inoculadas com o AltMV-T por meio de lâmina de corte embebida no inóculo. Duas folhas por planta foram cortadas nas nervuras primárias e secundárias. $\mathrm{O}$ mesmo procedimento foi realizado para as plantas-controle, que foram previamente pulverizadas com $50 \mathrm{~mL}$ de água destilada $+100 \mathrm{~mL}$ de "Tween 20 ".

Foram utilizadas 10 plantas para cada tratamento com, pelo menos, duas repetições e a porcentagem de inibição $(\mathrm{PI})$ foi calculada com base na fórmula: $\mathrm{PI}=(\mathrm{T} / \mathrm{C})$ $\mathrm{x} 100$ onde $\mathrm{T}=\mathrm{n}^{\circ}$ de plantas tratadas com sintoma e $\mathrm{C}=\mathrm{n}^{\circ}$ de plantas do controle com sintoma (VICENTE et al., 1977).

\section{RESULTADOS E DISCUSSÃO}

Com base nos resultados obtidos nos testes biológicos, verificou-se que o vírus isolado de Torenia sp. foi transmitido por inoculação mecânica para uma gama relativamente restrita de hospedeiros, ou seja, das vinte espécies de plantas inoculadas, apenas oito manifestaram sintomas (tabela 1). O vírus foi transmitido também por lâmina de corte.
Entre as hospedeiras sistemicamente infectadas, destacam-se as espécies de Chenopodiaceae. Dentre as Solanaceae, o vírus infectou apenas N. megalosiphon. Quanto às Amaranthaceae, das cinco espécies testadas duas foram sistemicamente infectadas; G. globosa apresentou lesões necróticas locais com halo avermelhado e as demais reagiram com infecção latente (tabela 1).

Manchas cloróticas, necróticas e mosaico sistêmico em $C$. amaranticolor e $C$. quinoa, lesões necróticas locais em G. globosa e ausência de sintomas na maioria das espécies de Solanaceae inoculadas podem estar associados aos vírus do gênero Potexvirus (BRUNT, 1997). É importante salientar que lesões necróticas locais em G. globosa já foram relatadas para o Bamboo mosaic virus (BaMV), Cassava common mosaic virus (CsCMV), Daphne virus $X$ (DVX), Foxtail mosaic virus (FoMV), Hydrangea ringspot virus (HdRSV), Narcissus mosaic virus (NMV), Papaya mosaic virus (PapMV) e PVX, embora a formação de halo vermelho tenha sido relatada apenas para os vírus DVX e PapMV (BRUNT, 1997). Quanto ao PVX, espécie tipo do gênero, o círculo de hospedeiros é principalmente limitado a Solanaceae, embora algumas espécies de Amaranthaceae e Chenopodiaceae sejam suscetíveis (BERCKS, 1970).

Vale lembrar que o vírus foi isolado de plantas de torênia aparentemente sem sintomas (infecção latente), fato esse que pode vir a causar sérios problemas às culturas, visto que, dependendo da hospedeira, da temperatura, fotoperíodo e outras condições, pode induzir sintomas drásticos nas plantas infectadas (HULL, 2002). Além disso, mesmo que o vírus não induza sintomas, como é o caso de Torenia sp., a hospedeira se torna uma potencial fonte de inóculo para outras espécies. Ainda digno de nota foi a indução de infecção latente em plantas de torênia sadias inoculadas com o vírus em estudo.

Outras hospedeiras que mostraram infecção latente, quando mecanicamente inoculadas, foram Z. elegans e A. viridis. Dentre os potexvírus, AltMV também induz latência em Z. elegans, além de Helianthus annus e Gypsophila repens (HAMMOND, 2006).

Como o círculo de hospedeiras e os sintomas induzidos pelo vírus isolado de torênia foram mais similares aos descritos para o AltMV (GEERING e THOMAS, 1999; HAMMOND, 2006; BAKER et al., 2006), ELISA-indireto com anti-soro contra esse vírus foi realizado, evidenciando relação sorológica positiva. O AltMV é um potexvirus descrito apenas em plantas ornamentais na Austrália, na Itália e nos Estados Unidos e infecta Alternanthera pungens, Portulaca grandiflora, Phlox stolonifera, Scutellaria longifólia e Crossandra infundibuliformis (GEERING e THOMAS, 1999; CIUFFO e TURINA, 2004; HAMMOND, 2006; BAKER et al., 2006). Levando-se 
em consideração que algumas espécies de potexvírus são antigenicamente relacionadas (FAUQUET et al., 2005), testes moleculares foram realizados, visando à correta identificação do vírus. Assim, um fragmento de cerca de $750 \mathrm{pb}$ foi obtido por meio de RT-PCR com oligonucleotídeos universais para potexvírus (GIBBS et al., 1998).

Após clonagem do fragmento e seqüenciamento de dois clones (TOR1 e TOR2), verificouse que as seqüências apresentaram identidade com regiões correspondentes à parte da polimerase de RNA dependente de RNA - RdRp (ORF 1) dos Potexvirus (KOONIN e DOLJA, 1993; GIBBS et al., 1998).

Os clones TOR1 e TOR2 apresentaram seqüências de nt com mínimas diferenças entre si, sendo que a identidade foi de $98,9 \%$ (tabela 2).

As maiores porcentagens de identidade observadas para TOR1 e TOR2, quando comparadas com seqüências homólogas dos demais potexvírus, foram observadas entre AltMV e PapMV (tabela 2).

De acordo com a nova proposta para demarcação de espécies de Potexvirus, identidades inferiores a $72 \%$ e $80 \%$, em nt e aa respectivamente, quando comparadas às seqüências da capa protéica ou da polimerase, indicam tratar-se de espécies diferentes (FAUQUET et al., 2005). As porcentagens de identidade entre AltMV x TOR1 e AltMV x TOR2 foram maiores que $92,69 \%$. Assim, com base na análise das seqüências obtidas, constatou-se que o vírus em estudo é o AltMV (AltMV-T). BAKER et al. (2006) também verificaram porcentagens de identidade em nt semelhantes às obtidas no presente trabalho entre AltMV e o vírus presente em $S$. longifolia, C. infundibuliformis e P. grandiflora.

A análise filogenética também corroborou com os demais resultados quanto à identidade do vírus isolado de torênia. Dessa forma, análise de máxima parcimônia (MP) de sequiências de nucleotídeos e aminoácidos de parte da RdRp, utilizando-se seqüência homóloga do Potato virus $M$ (Carlavirus) como grupo externo, evidenciou a presença de um grupo monofilético formado por TOR1, TOR2 e AltMV, sustentado por 100\% de "bootstrap" (figuras 2A, B). A topologia da árvore obtida evidenciou também que o AltMV e o vírus isolado de torênia compartilham um ancestral comum com o PapMV (clado sustentado por $99 \%$ de "bootstrap"). HAMMOND et al. (2006) sugerem que a relação sorológica entre o AltMV e PapMV descrita por GEERING e THOMAS (1999), combinada com a similaridade de sintomas em alguns hospedeiros, indicaram erroneamente que o AltMV poderia ser um isolado de PapMV.
Convém destacar que, dentre os potexvirus já descritos, no Brasil, já foi relatada a ocorrência do Bamboo mosaic virus (BaMV), Cactus virus X (CVX), Cassava common mosaic virus (CsCMV), Cymbidium mosaic virus (CymMV), Patchouli virus X (PaVX), PVX, White clover mosaic virus (WCIMV) e uma provável nova espécie, tentativamente denominada Caladium virus $\mathrm{X}$ (SILBERSCHMIDT, et al, 1941, COSTA e KITAJIMA 1972, CHAGAS et al., 1977, LIN et al., 1977, MULDER et al., 1987, MEISSNER et al., 1992, ARAGÃO et al., 1993, RIVAS et al., 2005). Além desses vírus, três novas espécies isoladas de Cactaceae, recentemente propostas por KOENIG et al (2004) foram relatadas por DUARTE e colaboradores (2005) em Hylocereus undatus, Opuntia tuna e Schlumbergera truncata (Cactaceae) e uma espécie ainda não identificada, porém sorologicamente relacionada com o AltMV, foi isolada de Portulaca oleracea 'oposita' (TOMOMITSU, 2007).

O primeiro passo para que se obtenham medidas adequadas de manejo e controle é a correta identificação do patógeno. Porém, a capacidade de infecção latente do AltMV (HAMMOND, 2006) torna difícil a sua detecção nas culturas e pode indicar uma distribuição mais ampla do que se acredita. Uma vez que os potexvírus são transmitidos facilmente por contato (FAUQUET et al., 2005) e podem ser disseminados na cultura por meio de instrumentos de poda, é necessário que medidas eficientes de controle sejam adotadas. Assim, extrato foliar de $M$. jalapa, pulverizado antes do corte das folhas de C. amaranticolor com lâmina infectada pelo AltMV-T, propiciou uma inibição da infecção de 83,3\%.É importante mencionar que extratos foliares de espécies com atividade inibidora de infecção viral vêm sendo testados no Laboratório de Fitovirologia e Fisiopatologia, do Instituto Biológico (SP), há varias décadas, e resultados promissores foram obtidos, destacando-se a utilização de $M$. jalapa visando controlar a infecção causada por vírus que infectam culturas como as de tomate, batata e abobrinha de moita (NORONHA et al. 1989; DUARTE et al. 1995; TOZETTO et al. 2002).

Vale lembrar que essa é a primeira vez que pesquisas, utilizando extratos foliares contendo substância inibidora de infecção viral, são realizadas visando o controle de vírus que infectam espécies ornamentais e os resultados abrem uma nova perspectiva de controle das viroses que acometem essas espécies. 
Tabela 1. Círculo de hospedeiras e sintomas induzidos pelo vírus isolado de Torenia sp. Table 1. Host rang and symptoms induced by virus isolated from Torenia sp.

\begin{tabular}{|c|c|c|c|c|c|}
\hline \multirow[t]{2}{*}{ Família } & \multirow{2}{*}{ Espécies } & \multicolumn{2}{|c|}{ Sintomas } & \multicolumn{2}{|c|}{ Recuperação em G. globosa } \\
\hline & & Local & Sistêmico & Local & Sistêmico \\
\hline \multirow[t]{5}{*}{ Amaranthaceae } & Alternanthera brasiliana & $\mathrm{AC}, \mathrm{M}$ & $\mathrm{MC}, \mathrm{DF}$ & + & + \\
\hline & A. tenella & A & A & $*$ & + \\
\hline & Amaranthus virides & A & A & $*$ & + \\
\hline & Celosia sp. & M & M & $*$ & $*$ \\
\hline & Gomphrena globosa & ANV & A & $*$ & $*$ \\
\hline Asteraceae & Zinnia elegans & A & A & + & - \\
\hline \multirow[t]{3}{*}{ Chenopodiaceae } & Chenopodium amaranticolor & MC & $\mathrm{CN}, \mathrm{MC}, \mathrm{MN}, \mathrm{NN}$ & $*$ & $*$ \\
\hline & C. quinoa & MC & $\mathrm{CN}, \mathrm{FN}, \mathrm{M}, \mathrm{MN}$ & $*$ & $*$ \\
\hline & C. murale & $\mathrm{MN}$ & $\mathrm{MP}, \mathrm{MN}, \mathrm{N}$ & $*$ & $*$ \\
\hline Scrophulariaceae & Torenia sp. & A & A & + & + \\
\hline Portulacaceae & Portulaca oleracea 'sativa' & M & M & $*$ & $*$ \\
\hline \multirow[t]{9}{*}{ Solanaceae } & Datura stramonium & A & A & - & - \\
\hline & Nicotiana benthamiana & A & A & - & - \\
\hline & N. clevelandii & A & A & 一 & - \\
\hline & N. debneyi & A & A & - & 一 \\
\hline & N. glutinosa & A & A & - & - \\
\hline & N. megalosiphon & DF & $\mathrm{M}, \mathrm{RC}$ & $*$ & $*$ \\
\hline & N. sylvestris & A & A & - & - \\
\hline & N. tabacum "White Burley" & A & A & - & - \\
\hline & N. tabacum "Xanthi" & A & A & 一 & - \\
\hline
\end{tabular}

$\mathrm{A}=$ ausente; $\mathrm{AC}=$ anéis cloróticos; $\mathrm{ANV}=$ anéis necróticos com halo vermelho; $\mathrm{CN}=$ clareamento de nervuras; $\mathrm{DF}=$ deformação foliar; $\mathrm{FN}=$ faixa-de-nervuras; $\mathrm{M}=$ mosaico $\mathrm{MC}=$ manchas cloróticas; $\mathrm{MP}=$ morte da planta; $\mathrm{MN}=$ manchas necróticas; $\mathrm{N}=$ necrose; $\mathrm{NN}=$ necrose acompanhando as nervuras; $\mathrm{RC}=$ redução no crescimento; $-=$ recuperação negativa; $+=$ recuperação positiva; $*=$ recuperação não realizada 
Tabela 2. Porcentagens de identidade de seqüências parciais de nucleotídeos (nt) e aminoácidos (aa) deduzidos dos clones de Torenia sp. (TOR1 e TOR2), comparadas a outras espécies de Potexvirus Table 2. Identity percentages of the partial sequence of nucleotides ( $\mathrm{nt}$ ) and deduced amino acids (aa) of Torenia sp. clones (TOR1 and TOR2) in comparison with other Potexvirus species

\begin{tabular}{lllll}
\hline Espécies de Potexvirus & *) & \multicolumn{2}{c}{ TOR 1 } & \multicolumn{2}{c}{ TOR 2 } \\
\hline & nt & aa & nt & aa \\
AltMV (NC007731) & 92,84 & 94,00 & 92,69 & 93,00 \\
BaMV (NC 001642) & 58,57 & 58,10 & 58,73 & 58,14 \\
CalVX (AY 727533) & 64,12 & 60,28 & 63,97 & 60,28 \\
ClYMV (NC 001753) & 65,34 & 67,76 & 65,34 & 67,29 \\
CsCMV (NC 001658) & 64,96 & 66,04 & 64,81 & 65,57 \\
CVX (NC 002815) & 64,80 & 65,74 & 64,50 & 65,28 \\
CymMV (AF 016914) & 59,07 & 60,30 & 59,07 & 59,81 \\
FoMV (NC 001483) & 62,34 & 59,53 & 62,18 & 59,07 \\
HdRSV (NC 006943) & 63,08 & 62,04 & 62,77 & 61,57 \\
HVX (AJ 620114) & 65,34 & 66,51 & 65,34 & 66,05 \\
LVX (NC 007192) & 62,26 & 60,75 & 62,41 & 60,45 \\
MinVX (NC 006948) & 62,92 & 59,81 & 63,07 & 59,81 \\
NMV (NC 001441) & 63,20 & 60,93 & 63,20 & 60,46 \\
NVX (AB 219105) & 62,41 & 61,39 & 62,26 & 60,93 \\
OpVX (AY 366209) & 64,47 & 65,74 & 64,47 & 65,28 \\
PAMV (S 73580) & 59,16 & 58,88 & 59,16 & 58,41 \\
PapMV (NC 001748) & 73,55 & 81,19 & 73,39 & 80,73 \\
PepMV (AJ 308445) & 59,29 & 60,46 & 59,29 & 60,00 \\
PIAMV (Z 21647) & 63,10 & 61,40 & 62,92 & 60,93 \\
PVX (AF 111193) & 64,01 & 65,59 & 63,86 & 65,58 \\
SchVX (AY 366207) & 62,62 & 64,35 & 62,46 & 63,89 \\
ScaVX (NC 004300) & 63,04 & 59,81 & 63,35 & 59,81 \\
SMYEV (D 12517) & 58,48 & 61,79 & 58,32 & 61,32 \\
TVX (NC 004322) & 62,61 & 63,38 & 62,30 & 65,91 \\
WCIMV (X 16636) & 59,46 & 56,07 & 59,30 & 55,60 \\
ZyVX (AY 366208) & 63,24 & 64,81 & 63,08 & 64,35 \\
TOR1 & - & - & 98,93 & 97,72 \\
\hline
\end{tabular}

$\mathrm{AltMV}=$ Alternanthera mosaic virus $; \mathrm{BaMV}=$ Bamboo mosaic virus; $\mathrm{CalVX}=\mathrm{Caladium}$ virus $\mathrm{X} ; \mathrm{ClYMV}=$ Clover yellow mosaic virus; $\mathrm{CsCMV}=$ Cassava common mosaic virus $; \mathrm{CVX}=$ Cactus virus $X ; \mathrm{CymMV}=$ Cymbidium mosaic virus; $\mathrm{FoMV}=$ Foxtail mosaic virus; $\mathrm{HdRSV}=$ Hydrangea ringspot virus $; \mathrm{HVX}=$ Hosta virus $X ; \mathrm{LVX}=$ Lily virus $X ; \mathrm{MinVX}=$ Mint virus $\mathrm{X} ; \mathrm{NMV}=$ Narcissus mosaic virus; $\mathrm{NVX}=$

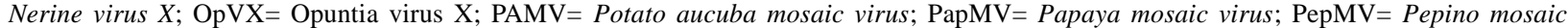
virus; $\mathrm{PlAMV}=$ Plantago asiatica mosaic virus; $\mathrm{PVX}=$ Potato virus $X$; SchVX= Schlumbergera virus $\mathrm{X} ; \mathrm{ScaVX}=\mathrm{Scallion}$ virus $\mathrm{X} ; \mathrm{SMYEV}=$ Strawberry mild yellow edge virus; $\mathrm{TVX}=$ Tulip virus $X ; \mathrm{WCIMV}=$ White clover mosaic virus; $\mathrm{ZyVX}=\mathrm{Zygocactus}$ virus $\mathrm{X} .(*)=\mathrm{N}^{\circ}$ de acesso no GenBank

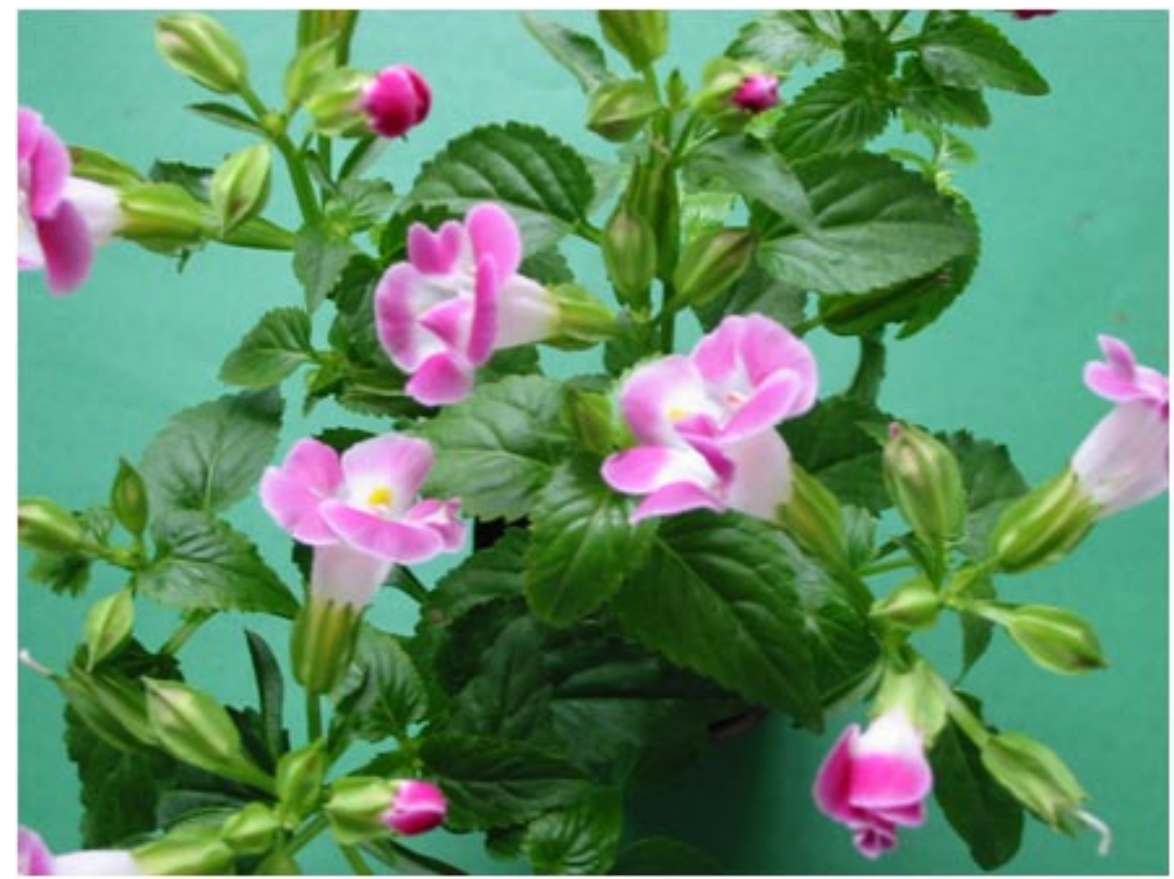

Figura 1. Torenia sp., proveniente de São José do Rio Preto (SP), Brasil.

Figure 2. Torenia sp., from São José do Rio Preto (SP), Brazil. 


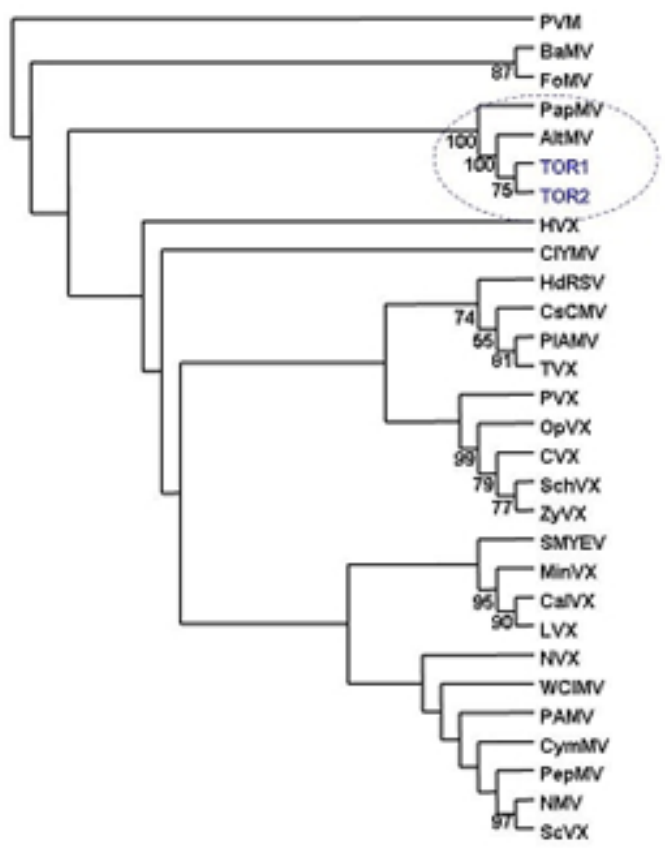

A

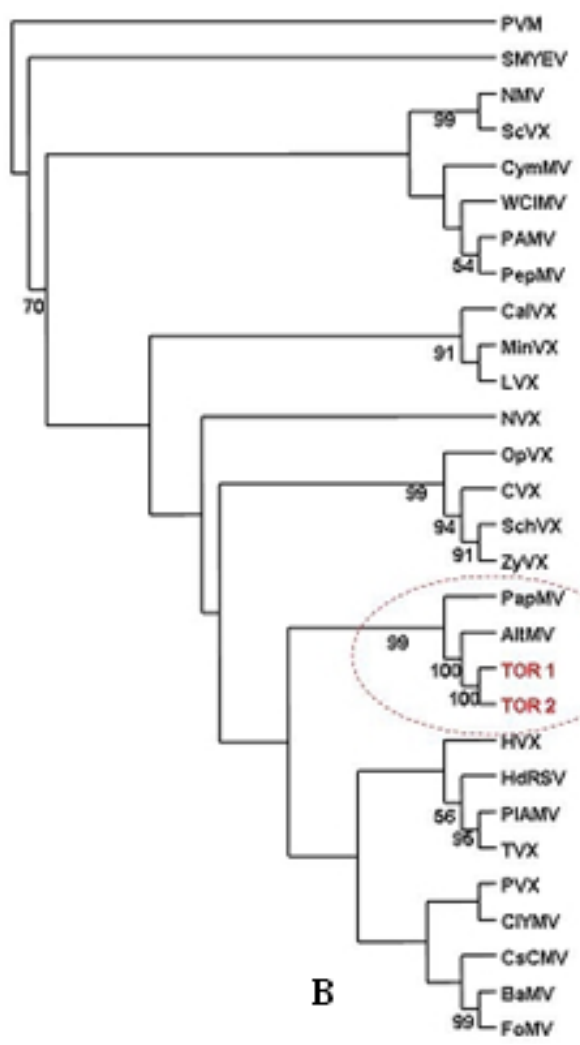

Figura 2. Árvores filogenéticas, obtidas por análise de máxima parcimônia, de sequiências de nucleotídeos (A) e aminoácidos deduzidos (B) de parte da polimerase de RNA dependente de RNA (RdRp) de espécies de Potexvirus (ver tabela 2 para os nomes das espécies e $n^{\circ}$ de acesso no GenBank) e dos clones de Torenia sp. (TOR 1 e TOR 2). Seqüência do Potato virus M (PVM) - NC 001361 foi utilizada como grupo externo. Os valores de "bootstrap" (1000 réplicas) estão indicados nos ramos.

Figure 2. Phylogenetic trees obtained by Maximum parsimony analises of nucleotide sequences $(\boldsymbol{A})$ and deduced amino acids (B) from RNA-dependent RNA polymerase (RdRp) of Potexvirus species (GenBank accession number, as well as the name of viruses are indicated in Table 2) and Torenia sp. clones (TOR 1 and TOR 2). Potato virus M (PVM) - NC 001361 sequence was used as out group. The bootstrap values (1000 replicates) are indicated near the branches.

\section{REFERÊNCIAS}

ALEXANDRE, M.A.V.; RIVAS, E.B.; TORZETTO, A.R.P.; DUARTE, L.M.L. Lista Comentada sobre a Ocorrência Natural de Vírus em Plantas Ornamentais no Brasil. Instituto Biológico, São Paulo, p. 55, 2005a.

ALEXANDRE, M.A.V; SEABRA, P.V.; RIVAS, E.B.; DUARTE, L.M.L; GALETTI, S.R. Vírus, viróides, fitoplasmas e espiroplasmas detectados em plantas ornamentais no período de 1992 a 2003. Revista Brasileira de Horticultura Ornamental, Campinas, v.11, p. 49-57, $2005 b$.

ALTSCHUL, S.F.; GISH, W.; MILLER, W.; MYERS, E.W.; LIPMAN, D.J. Basic local alignment search tool. Journal of Molecular Biology, London, v. 215, p. 403-410, 1990.

ARAGÃO, F.J.L.; MARINHO, V.L.A.; KITAJIMA, E.W. Cactus virus $\mathrm{X}$ in Cactaceae in Brazil and a novel method to purify it directly from cactus tissues. Fitopatologia Brasileira, Brasília, v. 18, p. 12-117, 1993.
BAKER, C.A.; BREMAN, L.; JONES, L. Alternanthera mosaic virus found in Scutellaria, Crossandra, and Portulaca spp. in Florida. Plant Disease, St. Paul, v. 90, n. 6, p. 833, 2006.

BERCKS, R. Potato vvirus X. C.M.I./A.A.B. Descriptions of plant viruses, Perthshire, n.4, 1970.

BRUNT,A.A.; CRABTREE, K.; DALLWITZ, M.J.; GIBBS, A.J.; WATSON, L. Viruses of plants - Descriptions and lists from the VIDE Database. Cab International, Wallinford, 1484 p., 1997.

CIUFFO, M.; TURINA, M. A potexvirus related to Papaya mosaic virus isolated from moss rose (Portulaca grandiflora) in Italy. Plant Pathology, Oxford, v. 53, n. 4, p. 515, 2004.

CHAGAS, C.M.; NORONHA, A.B., JULY, J.R. Ocorrência de um complexo viral em Cymbidium no Brasil. O Biológico, São Paulo, v. XLIII, p. 72-77, 1977. 
COSTA, A.S.; KITAJIMA, E.W. Cassava common mosaic virus. CMI/AAB Descriptions of plant viruses, Perthshire, n.90, 1972.

DUARTE, L.M.L.; ALEXANDRE, M.A.V.; NORONHA, A.B.; VICENTE, M. Behaviour of tobacco plants, singly and doubly infected by potato virus $\mathrm{X}$ and potato virus $\mathrm{Y}$ necrotic strain, in the presence of some natural inhibitors. Microbios Letters, Cambridge, v. 45, p. 131-137, 1990.

DUARTE, L. M. L.; HARAKAVA, R.; ALEXANDRE, M.A.V.; RIVAS, E.B.; GALLETI, S.R.; BARRADAS, M.M. Diversity of Potexvirus in Cactaceae species. Virus Reviews and Research, Rio de Janeiro, v.10, n. sup. 1, p.88$88,2005$.

DUARTE, L.M.L.; NORONHA, A.B.; ALEXANDRE, M.A.V.; VICENTE, M; CHAGAS, C.M. Action of three plant-virus inhibitors on potato virus X. Microbios, Cambridge, v. 84, n. 7, p. 13-20, 1995.

FAUQUET, C.M.; MAYO, M.A.; MANILOFF; DESSELBERGER, U.; BALL, L.A. Virus taxonomy. Eighth report of the International Committee on Taxonomy of Viruses. San Diego: Elsevier Academic Press, 2005. 1259 p.

GEERING, A.D.W.; THOMAS, J.E. Characterization of a virus from Australia that closely related to papaya mosaic potexvirus. Archives of Virology, Vienna, v.144, n. 3, p. 577-592, 1999.

GIBBS, A.; ARMSTRON, J.; MACKENZIE, A.M.; WEILLER, G.F. The GPRIME package: computer programs for identifying the best regions of aligned genes to target in nucleic acid hybridization base on diagnostic tests, and their use with plant viruses. Journal of Virological Methods, Amsterdam, v. 74, n. 2, p. 67-76, 1998.

GILBERT, D.G. A biosequence editor and analysis application. In: "SeqPup" Indiana University, Bloomington, 1995, v. 0.6f.

HAMMOND, J.; REINSEL, M.D.; LANGO-MAROON, C.J. Identification and full sequence of an isolate of Alternanthera mosaic potexvirus infecting Phlox stolonifera. Archives of Virology, Vienna, v. 151, n. 3 p. 477-493, 2006.

HULL, R. Matthews's plant virology. San Diego: Academic Press, 2002. 1001 p.

JUNQUEIRA, A.H.; PEETZ, M. S. Os pólos de produção de flores e plantas ornamentais do Brasil: uma análise do potencial exportador. Revista Brasileira de Horticultura Ornamental, Campinas, v. 8, n. 1/2, p. 25-47, 2002.

JUNQUEIRA, A.H.; PEETZ, M. S. Exportações brasileiras de flores e plantas ornamentais: projeções indicam novo recorde para 2007. Fonte: Hortica Consultoria e Treinamento, a partir de dados do Ministério do Desenvolvimento, Industria e Comercio. Secretaria do Comercio Exterior. 2007.

KIYUNA, I.; FRANCISCO, V.L.F.S.; COELHO, P.J.; CASER, D.V., ASSUMPÇÃO, R., ÂNGELO, J.A. A floricultura brasileira no início do século XXI: O perfil do produtor. Revista Brasileira de Horticultura Ornamental, Campinas ,v. 8 , n. 1/2, p. $57-76,2002$.

KIYUNA, I.; FRANCISCO, V.L.F.S.; COELHO, P.J. Flores: desempenho do comércio exterior em 2006. Análises e Indicadores do Agronegócio, Campinas, v. 1, n 2, 2007.
KOENIG, R. Indirect ELISA methods for the brad specificity detection of plant viruses. Journal of General Virology, Rading v. 55, p. 53-62, 1981.

KOENIG, R.; PLEIJ, C.W.A.; LOSS, S.; BURGERMEISTER, W.; AUST, H.,; SCHIEMANN, J. Molecular characterisation of potexviruses isolated from three different genera in the family Cactaceae. Archives of Virology, Vienna, v. 149, p. 903-914, 2004.

KOONIN, E.V.; DOLJA, V.V. Evolution and taxonomy of positive-strand RNA viruses: implication of comparative analysis of amino acid sequences. Critical Reviews in Biochemistry and Molecular Biology, Boca Raton, v. 28, p. $375-430,1993$.

LIN, M.T.; KITAJIMA, E.W.; CUPERTINO, F.P.; COSTA, C.I. Partial purification and some properties of Bamboo mosaic virus. Phytopathology, London, v.67, p.1439-1443, 1977.

MEISSNER, F.O.; KITAJIMA, E.W.; HABE, M.H.; BARROS, T.S.L; PARENTE, C.O. Infecção natural de Patchuli (Pogosternum patchuli) por um Potexvirus. Fitopatologia Brasileira, Brasília, v. 17, p.179, 1992.

MULDER, J.G; KITAJIMA, E.W.; LIN, M.T., RIBEIRO, S.G. Characterization of white clover mosaic virus, isolated from clover (Trifolium sp.) in the state of Paraná, Brazil. Fitopatologia Brasileira, Brasília, v. 12, p. 263-269, 1987.

NORONHA, A.B.; ALEXANDRE, M.A.V.; DUARTE, L.M.L.; VICENTE, M. Controle alternativo de fitovírus com a utilização de inibidores naturais. O Biológico, São Paulo, v. 58, p. 7-12, 1996.

NORONHA, A.B.; DUARTE, L.M.L.; ALEXANDRE, M.A.V.; VICENTE, M. Inhibition of tomato spotted wilt virus (TSWV) systemic infection in tomato plants. Fitopatologia Brasileira, Brasília, v. 14, p. 283-287, 1989.

RIVAS, E.B.; DUARTE, L.M.L.; ALEXANDRE, M.A.V.; GALLETI, S.R.; HARAKAVA, R.; FERNANDES, F.M.C. Caladium virus $\mathrm{X}$, a new Potexvirus from Caladium bicolor (Araceae). Journal of Plant Pathology, Oxford, v. 87, n. 2, p. 109-114, 2005.

SILBERSCHMIDT, K.M.; NOBREGA, N.R.; KRAMER, M. Sobre as variantes dos virus $\mathrm{X}$ das batatinhas no Estado de São Paulo. Arquivos do Instituto Biológico, São Paulo, v. 12 , p. $27-58,1941$

SWOFFORD, D. L. PAUP*: Phylogenetic Analysis Using Parsimony (* and related methods). Version 4.0. Sinauer Associates, Massachusetts, 2002.

TOMOMITSU, A.T. Ecologia de fitovírus isolado de espécie ornamental. São Paulo: Centro de Ciências Biológicas e da Saúde, 2007. 46p. (Monografia de conclusão do Curso de Ciências Biológicas) - Universidade Presbiteriana Mackenzie, São Paulo, 2007.

TOZETTO, A.R.P.; CATTAI, M.B.; DUARTE, L.M.L.; ALEXANDRE, M.A.V.; RIVAS, E.B. Controle do Zucchini yellow mosaic vírus em abobrinha de moita com extrato foliar de Mirabilis jalapa. Arquivos do Instituto Biológico, São Paulo, v.69, p. 229-334, 2002.

VICENTE, M.; NORONHA,AB.; COLAMARINO,E. Modo de ação de um inibidor de vírus fitopatogênicos extraídos das folhas de Chenopodium amaranticolor Coste \& Reyn. Arquivos do Instituto Biológico, São Paulo, v.44, p. 185187, 1977. 